\title{
Enerji Verimli Bina Tasarımı için Yapay Sinir Ağları ile Isıtma Soğutma
} Yükünün Belirlenmesi

\section{Prediction of Heating- Cooling Load By Artificial Neural Networks for Energy Efficient Building Design}

\author{
Merve ERTOSUN YILDIZ ${ }^{1, a,}$, Figen BEYHAN ${ }^{1, b}$, Muhammed Kürşad UÇAR ${ }^{2}$ \\ ${ }^{1}$ Mimarlık Bölümü, Mimarlık Fakültesi, Gazi Üniversitesi, 06570, Çankaya, Ankara, Türkiye \\ a'merveertosun@gazi.edu.tr, bfbeyhan@gazi.edu.tr \\ ahttps://orcid.org/0000-0002-5362-1666 bhttps://orcid.org/0000-0002-4287-1037 \\ ${ }^{2}$ Elektrik-Elektronik Mühendisliği, Mühendislik Fakültesi, Sakarya Üniversitesi, 54050, Serdivan, Sakarya, Türkiye \\ mucar@sakarya.edu.tr \\ https://orcid.org/0000-0002-0636-8645
}

\section{Özet:}

Binalar tüketilen enerjinin yaklaşı \%40'ından sorumludur. Binaların konfor koşulları gözetilerek, ihtiyaç duyacağı enerji talebinin karşılanması önemlidir. Tasarım sürecinde alınan kararlar, binaların enerji verimliliği düzeylerini etkilemektedir. Enerji simülasyon programlarının çoğu zaman alıcı yöntemler içermektedir. Daha hızlı çözüm yöntemlerine duyulan ihtiyaç bağlamında, binaların ısıtma ve soğutma yüklerinin yapay sinir ağları tabanlı yöntemlerle modellenerek enerji verimliliğinin arttırılması amaçlanmışıtır. Literatürden elde edilen, binaların duvar ve çatı alanları ile toplam yükseklik, yönelim, cam yüzeylerin alanı ve dağılımı parametrelerinden oluşan 768 veri seti, eğitim ve test olmak üzere iki parçaya ayrılmış, yapay sinir ağları ile ısıtma ve soğutma yüklerinin hesabı için iki ayrı model oluşturulmuştur. Isıtma ve soğutma yüklerinin enerji talebini belirlemek için geliştirilen modellerin $\mathrm{R}$ performans değeri sırasıyla 0,99 ve 0,99 olarak tespit edilmiştir. Yapay sinir ağları tabanlı modelin, binalarda ısıtma ve soğutma yükü için ihtiyaç duyulan enerji talebinin hesaplanmasında simülasyon programları yerine kullanılabileceği göstermektedir.

Anahtar Kelimeler: Bina Enerji Performansı, Enerji Verimliliği, Yapay Sinir Ağları, Makine Öğrenimi

\begin{abstract}
:
Buildings are responsible for almost $40 \%$ of energy consumed. It is important to supply the energy demand of the buildings by considering the comfort conditions. Decisions taken during the design process affect the energy efficiency levels of buildings. Energy simulation programs often contain timeconsuming methods. In the context of the need for faster solution methods, it is aimed to increase energy efficiency by modeling the heating and cooling loads of buildings with artificial neural networks-based methods. The 768 data sets, consisting of wall and roof areas, total height, orientation, area and distribution of glass surfaces obtained from the literature, was divided into two parts as training and testing. After, two different models were created for the calculation of heating and cooling loads with artificial neural networks. The R performance values of the models were determined as 0.99 and 0.98 , respectively. The artificial neural network-based model can be used instead of simulation programs to predict building's energy demand for heating-cooling loads.
\end{abstract}

Key words: Building Energy Performance, Energy Efficiency, Artificial Neural Networks, Machine Learning 


\section{Giriş}

Dünyada, toplam enerji tüketiminden kaynaklı sera gazı emisyonlarının önemli ve giderek artan kısmından yapılı çevreler sorumludur. Yapılı çevre, insanlar tarafından inşa edilen her yapıyı kapsamaktadır ve binalar, kentlerde başlıca enerji tüketicileri olarak tanımlanmaktadır [1]. Binalarda enerji, aydınlatma, ısıtma, soğutma, havalandırma ev aletleri, sıcak su gibi çeşitli ihtiyaçlara yönelik olarak tüketilmektedir. Uluslararası Enerji Ajansı (IEA) verilerine göre, bina işletimi sürecinde harcanan enerji toplam küresel nihai enerji tüketiminin yaklaşık üçte birini oluşturmakta ve harcanan enerjinin büyük bir kısmının 1sıtma, soğutma ve sıcak su temini amaçlı kullanılmaktadir [2].

Binalarda enerji kullanımının tahmini, enerji tasarrufu sağlamak ve çevresel etkiyi azaltmak amacıyla enerji performanslarını iyileştirmek için oldukça önemlidir [3]. Bir çok ülkede enerji talebini düşürmek ve sera gazı oluşumunu azaltmak için binalar, gelişebilecek kilit bir sektör olarak düşünülmekte ve bina sektörüne yönelik çalışmalar yürütülmektedir.

Bir binanın enerji tüketimi fiziksel özelliklerine, kullanımına ve konumuna bağlı olarak değişmektedir [4]. Binaların konfor koşulları gözetilerek, ihtiyaç duyacağı enerji talebinin karşılanması gerekmektedir. Binaların tasarım sürecinde alınan kararları, enerji performans düzeylerini etkilemektedir. Tasarım süresince, bir binanın enerji performasına yönelik çalışmalarla bina kullanım ve işletim sürecinde tüketeceği enerji miktarı tahmini dinamik simülasyon araçlarıyla yapılmaktadır ancak bu zaman alıcı bir süreçtir. Ayrıca simülasyon araçlarının karmaşıklığı ve bina hakkında ayrıntılı bilgi gereksinimi, kullanıcılar açısından caydırıcı olabilmektedir [5]. Bu nedenle bilinen özelliklerle öğrenilen verilere dayanarak tahminler üzerine odaklanan makine öğrenimi, binaların enerji talep tahminlemesi için yüksek doğruluğu ve uygulama kolaylığı [6] ile güncel bir yaklaşım olarak kullanım alanı bulmaktadır. Yapılan bir çalışmada, yapay sinir ağları (YSA) kullanarak yaz ve kış aylarında bir binanın enerji tüketimi için tahmini değerler hesaplanmış ve YSA' nın büyük bir veri setinin tahmini için uygun olduğu sonucuna varılmıştır [7]. Destek vektör regresyonu (SVR), YSA, sınıflandırma ve regresyon ağacı gibi çeşitli makine öğrenim tekniklerinin kullanılarak binaların 1sıtma ve soğutma yükleri için gerekli enerji performansının tahminlendiği bir çalışmada sonuçlar bu tekniklerin enerji performans tahmini için \% 4'ün altında hata oranına sahip olduğunu göstermektedir [8]. Madrid'deki bir otelin saatlik HVAC enerji tüketimini tahmin etmek amaciyla YSA performans1, rassal orman (random forest) modeli (RF) ile karşılaştırılarak değerlendirilmiştir. Her iki model de yüksek doğruluklu ve benzer tahmin oranlarının çıkması her iki modelin de pratikte uygulanabilirliğini göstermiştir [9]. Farklı bina türleri için kullanılabilecek kolay, daha az zaman alan ve güvenilir bir enerji tahmin modeli oluşturmak amacıyla çoklu Regresyon (MR) tekniği kullanılarak üniversite binalarının günlük elektrik kullanımını tahmin etmek için bir yöntem geliştirilmiş ve model sonuçları, idari bina için \% 12 ve akademik bina için \%' 13'lük Normalleştirilmiş Kök Ortalama Kare Hatası (NRMSE) ile ilişkilendirilmiştir [10]. Literatürde yer alan tüm çalışmalar, makine öğrenimi ile binaların enerji talebini belirlemenin mümkün olduğunu, kullanılan veri setine bağlı olarak farklı yöntemlerin denenerek en uygun sonucun bulunabilirliğini ve bu tekniklerin kısa sürede yüksek doğruluklu sonuçlar verdiğini göstermektedir [5], [6], [11][15]. 
Binalarda enerji performans tahmininin enerji verimli bina tasarımı aşamasında önemli bir adım olduğu düşünülerek bu çalışmada, literatürde yer alan ve binaların duvar ve çatı alanları ile toplam yükseklik, yönelim, cam yüzeylerin alanı ve dağılımı parametrelerinden oluşan veri seti ile 1sıtma ve soğutma yüklerinin YSA yöntemi ile hesaplanması ve bu parametrelerin sonuç tahminlerine etkisinin belirlenmesi amaçlanmıştır. İlk olarak Spearman Korelasyon Katsayısı kullanılarak veri setine özelik seçme işlemi uygulanmıştır. Seçilen özellikler üzerinden 1sıtma ve soğutma yükleri tahmini için YSA ile iki ayrı model oluşturulmuştur.

\section{Materyal ve Yöntem}

Şekil 1'deki uygulama adımlarına göre kurgulanan çalışmada ilk olarak toplam sekiz bina parametresi girdi verisi olarak kullanılmıştır. Girdi verilerine özellik seçme algoritması uygulanarak ısıtma soğutma yüküne yanı çıktı verisine etkiyen en önemli özellikler belirlenmiş ve seçilen özellikler üzerinden her bir yük için YSA yardımıyla modeller oluşturulmuştur.

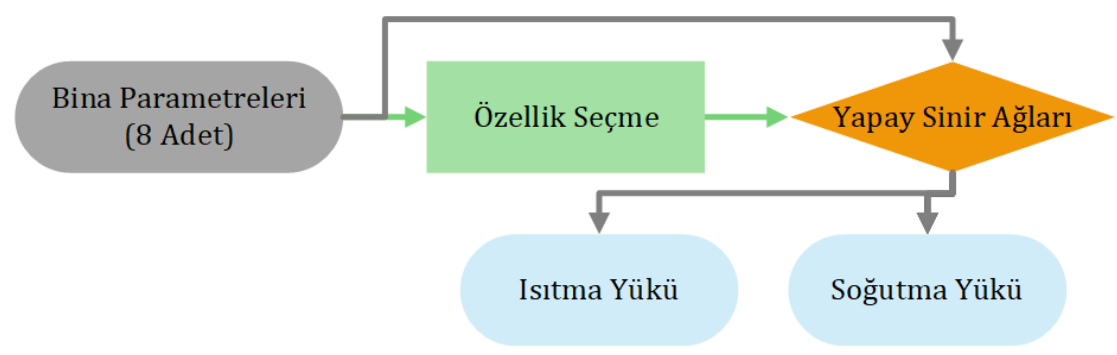

Şekil 1. Çalışma uygulama süreci

\subsection{Verilerin Toplanması}

Çalışmada açık kaynak kodlu UCI makine öğrenimi veri deposunda yer alan veri seti kullanılmıştır [16]. Aynı hacme, farklı yüzey alanları ve boyutlarına sahip binaların Ecotect'te simüle edilmesiyle oluşturulan veri setinde " $3.5 \times 3.5 \times 3.5$ " boyutlarında bir küp modül olarak belirlenmiş ve on sekiz modül kullanılarak on iki farklı yapı formu elde edilmiştir (Şekil 2). 


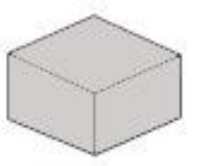

0.98

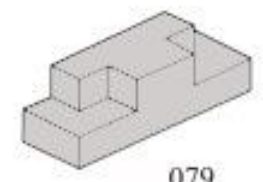

0.79

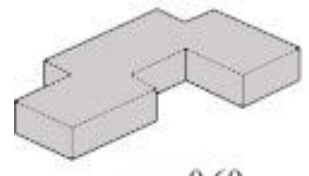

0.69

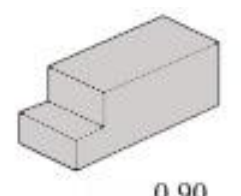

0.90

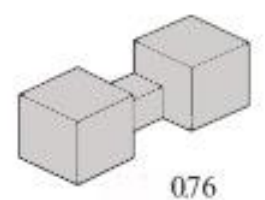

076

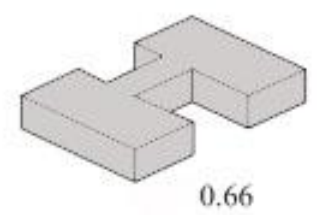

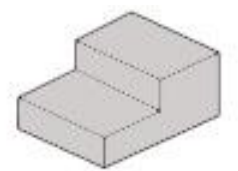

0.86

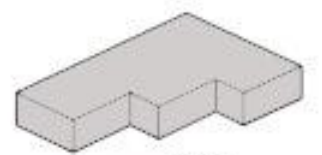

0.74
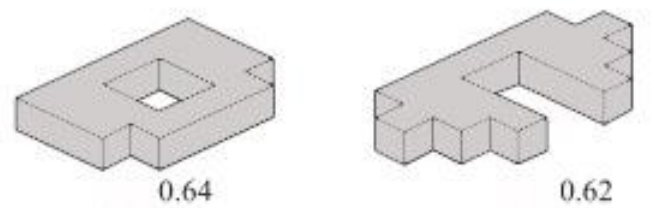

Şekil 2. Bina formları ve bağıl kompaktlık değerleri ([8])

Aynı tip malzeme kullanılarak oluşturulan bina simülasyonlarında, bina kullanıcıların hareketsiz olduğu varsayılmıştır. Senaryolar oluşturulurken, binalar doğu, batı, kuzey ve güney olarak dört biçimde yönlendirilmiş ve yapı cam alanları oranlarının $\% 10, \% 25$ ve $\% 40$ olacak şekilde üç farklı boyutta düşünülmüştür. Aynı zamanda cam yüzeyler aşağıda sıralanan oranlara göre cephe yüzeylerine konumlandırılmıştır:

1. Kuzey cephede $\% 55$ diğer cephelerde $\% 15$;

2. Güney cephede $\% 55$ diğer cephelerde $\% 15$;

3. Doğu cephede $\% 55$ diğer cephelerde $\% 15$;

4. Batı cephede $\% 55$ diğer cephelerde $\% 15$;

5. Her cephede $\% 25$;

6. Hiçbir cephede cam alanı mevcut değil.

Oluşturulan alternatifler sonucu her biri beş cam alanı dağılımına sahip on iki bina formu ve üç cam alanı varyasyonu ile dört yönelim için $5 \times 12 \times 3 \times 4=760$ bina ile hiç cam kullanılmayan dört yönelim (4×12) toplamda 768 bina verisi elde edilmiştir. Simülasyonlarda iç mekân koşulları, nem $\% 60$, hava akış hızı $0,30 \mathrm{~m} / \mathrm{s}$, sıcaklık $19-24{ }^{\circ} \mathrm{C}$, aydınlatma seviyesi $300 \mathrm{~lx}$ ve kullanıcıların da 0,6 clo giysili olarak işlenmiştir. Veri setine ait detaylı bilgiler [17] numaralı kaynakta yer almaktadır. Veri seti, konaklama amacıyla tasarlanan binalara ait yüzey alanı, bina hacminin yüzey alanına oranı olan bağıl kompaktlık, çatı alanı, duvar alanı, yönelim, yükseklik, cam alanı ve cam alanı dağılımlarına ait sekiz girdi parametresi ile 1sıtma ve soğutma yüklerine ait iki çıktı parametresinden oluşmaktadır (Tablo 1.). 
Tablo 1. Verilerin Dağılımı

\begin{tabular}{|c|c|c|c|c|c|}
\hline & & \multirow{2}{*}{ Veri seti } & \multicolumn{3}{|c|}{$n=768$} \\
\hline & & & Ort & & Std \\
\hline \multirow{8}{*}{ Girdi } & $\mathrm{X} 1$ & Bağıl Kompaktlık & 0,76 & \pm & 0,11 \\
\hline & $\mathbf{X 2}$ & Yüzey Alanı & 671,71 & \pm & 88,09 \\
\hline & $\mathrm{X3}$ & Duvar Alanı & 318,50 & \pm & 43,63 \\
\hline & X4 & Çatı Alanı & 176,60 & \pm & 45,17 \\
\hline & $\mathrm{X5}$ & Toplam Yükseklik & 5,25 & \pm & 1,75 \\
\hline & X6 & Yönlenme & 3,50 & \pm & 1,12 \\
\hline & $\mathbf{X} 7$ & Cam Alanı & 0,23 & \pm & 0,13 \\
\hline & X8 & Cam Alanı Dağılımı & 2,81 & \pm & 1,55 \\
\hline \multirow{2}{*}{ Çıktı } & Y1 & Isıtma Yükü & 22,31 & \pm & 10,09 \\
\hline & Y2 & Soğutma Yükü & 24,59 & \pm & 9,51 \\
\hline
\end{tabular}

Binanın yüzey alanı, duvar, çatı ve zemin alanlarının toplamıdır. Cam alanı, cam, çerçeve ve kanattan oluşan kaba açıklık kullanılarak ölçülen alandır. Bu alanın tüm bina yüzeyindeki oranı da cam alanı dağılımı olarak adlandırılmıştır (Şekil 3).

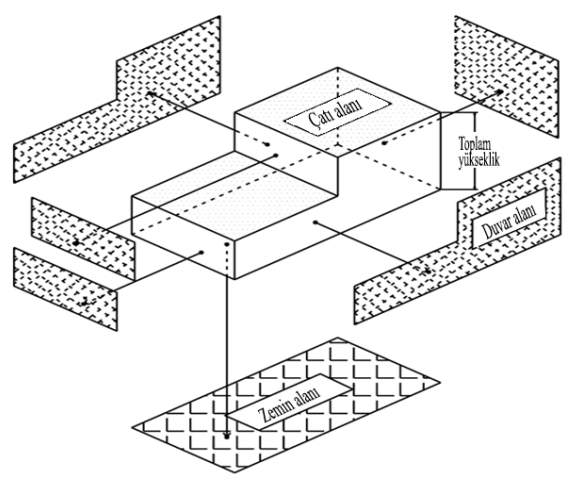

Şekil 3. Bina alanları tanımları[8]

\section{2. Özellik Seçimi}

Daha az hesaplama yükü ile daha yüksek başarım elde edilebilmek amacıyla kullanılan özellik seçimi algoritmaları, veri kümesinde yer alan en önemli ve etkili özelliklerin seçilerek veri tabanına ait özellik sayısının azaltılması işlemi olarak tanımlanabilir. Bu çalışmada iki sürekli değişken arasındaki ilişkiyi belirlemeye yarayan "Spearman Korelasyon Katsayıları" özellik seçme algoritması olarak kullanılmıştır [18]. Error! Reference source not found.'de bina parametrelerine ait özellikler ile ısıtma ve soğutma yükleri arasındaki ilişki korelasyon katsayılarına(R) göre özetlenmiştir. R değerlerinin farklı olması, her bir parametrenin sonuç çıktısına etkisinin farklı olduğunun göstergesidir. Her iki sonuç değeri için de özellikler yükseklik, 
çatı alanı, bağıl kompaktlık, yüzey alanı, duvar alanı, cam alanı, cam alanı dağılımı ve yönlenme olarak sıralanmıştır.

Tablo 2. Seçilen Özellikler

\begin{tabular}{ccc|ccc}
\multicolumn{1}{c}{ Isitma Yükü } & \multicolumn{3}{c}{ Soğutma Yükü } \\
\hline ÖN & Özellikler & $\mathbf{R}$ & ÖN & Özellikler & $\mathbf{R}$ \\
\hline 5 & Yükseklik & 0,86 & 5 & Yükseklik & 0,86 \\
\hline 4 & Çatı alanı & 0,80 & 4 & Çatı alanı & 0,80 \\
\hline 1 & Bağ1l kompaktlık & 0,62 & 1 & Bağıl kompaktlık & 0,65 \\
\hline 2 & Yüzey alanı & 0,62 & 2 & Yüzey alanı & 0,65 \\
\hline 3 & Duvar alanı & 0,47 & 3 & Duvar alanı & 0,42 \\
\hline 7 & Cam alanı & 0,32 & 7 & Cam alanı & 0,29 \\
\hline 8 & Cam alanı dağılımı & 0,07 & 8 & Cam alanı dağılımı & 0,05 \\
\hline 6 & Yönlenme & 0,00 & 6 & Yönlenme & 0,02 \\
\hline
\end{tabular}

ÖN: Özellik Numarası, R: Korelasyon Katsayısı

\subsection{Yapay Sinir A}

YSA, en çok uygulanan veriye dayalı enerji tüketim tahmin yöntemlerinden biridir ve çoğu tahmin problemini çözmeyi sağlayan esnek ve uyarlanabilir modellerdendir [15]. İnsan beynindeki sinir ağlarından ilham bu teknikte işlem, ağdaki katman sayısı kadar ve model verilere tam olarak uyana kadar tekrarlanmaktadır [13]. Her tür girdi verisini kullanarak kısa ila uzun vadeli tahminler için uygulanabilirliği, gömülü sistemlere entegre edilebilmesi gibi özellikleri nedeniyle bu çalışmada modelleme için YSA yöntemi tercih edilmiştir.

\subsection{Sonuç Performansların Değerlendirilmesi}

Veriye dayalı modellerin performansı veya doğruluğu, gerçek ve tahmin edilen sonuçlara dayalı çeşitli ölçümler hesaplanarak değerlendirilmektedir. Genel olarak, Korelasyon Katsayısı $(R)$, Açıklayıcılık Katsayısı $\left(R^{2}\right)$, Ortalama Mutlak Sapma (MAD) ve Ortalama Hata Karesi (MSE), Ortalama Kare Yüzde hatası (MSPE), Ortalama Karakök Sapması (RMSE), Ortalama Mutlak Yüzde Hata (MAPE) ve Varyasyon/Varyans Katsayısı(CV) yöntemleri kullanılarak sonuç performansları yorumlanmaktadır [11], [15], [19]. Bu çalışmada, RMSE, MAPE, R, $R^{2}$, MAD VE MSE kullanılmıştır. $R^{2}$ ve $R$ değerlerinin bire yakın olması; RMSE, MAPE, MSE, SH ve MAD değerlerinin ise sıfıra yakın olması model performansının yüksek olduğunun göstergesidir. 


\section{Tahmin Sonuçları}

Yapılan çalışmada literatürden elde edilen veri seti ikiye ayrılmış ve YSA modeli uygulanmıştır. Veri setinin \%75'i modeli eğitmek için kullanılırken, \%25' lik kısım ise test etmek için kullanılmıştır (Tablo 3). YSA modeli insan beyni örnek alınarak geliştirilmiş bir modeldir. Temel bir YSA modeli girdi katmanı, gizli katman ve çıktı katmanından oluşmaktadır. Yapılan çalışmada, girdi katmanı, modelde kullanılan özellik sayısı; çıktı katmanı da tahminlenmesi istenen çıktı sayısı kadardır. Gizli katmanlarda yer alan nöron sayısı için herhangi bir matematiksel test bulunmamaktadır [20]. En verimli tahmin sonuçlarına ulaşmak için gerekli nöron sayısı bulmak amacıyla çeşitli denemeler yapılmış ve 10 nöronun tahmin sonuçları için yeterli olduğu kanısına varılmıştır.

Tablo 3. Veri setinin eğitim ve test dağılımı

\begin{tabular}{cccc} 
Veri Seti & Ĕgitim (\%75) & Test (\%25) & Toplam \\
\hline Isıtma & 576 & 192 & 768 \\
\hline Soğutma & 576 & 192 & 768 \\
\hline
\end{tabular}

Konut işlevli binaların, tasarım parametrelerine bağlı olarak ısıtma ve soğutma yüklerini tahmin etmek için sekiz adet YSA modelleri oluşturulmuştur. Her modelde girdi olarak farklı sayıda tasarım parametresi kullanılmıştır. Isıtma yükü tahmininde oluşturulan tahmin sonuçlarının performans değerleri tablosu Tablo 4'tür. Tabloda yer alan özellik sayısı tahmin modelinde kaç özellik kullanıldığını; özellik numarası da modelde girdi için kullanılan özelliklerin (tasarım parametrelerinin) numaralarını göstermektedir. Tabloda yer alan performans değerlendirme kriterler değerleri incelenerek en başarılı tahmin modelinin 6 özelliğin girdi parametreleri olarak kullanıldığı altıncı model olduğu görülmektedir (Tablo 4).

Tablo 4. Isıtma yükü tahmini için model performansları

\begin{tabular}{|c|c|c|c|c|c|c|c|c|}
\hline \multicolumn{2}{|r|}{ Özellikler } & \multicolumn{7}{|c|}{ Performans Değerlendirme Kriterleri } \\
\hline ÖS & ÖN & MAPE & RMSE & MAD & SH & $\mathbf{R}$ & $\mathbf{R}^{2}$ & MSE \\
\hline 1 & 5 & 17,06 & 4,51 & 3,44 & 4,53 & 0,86 & 0,74 & 20,33 \\
\hline 2 & $5-4$ & 16,41 & 4,31 & 3,28 & 4,33 & 0,85 & 0,72 & 18,58 \\
\hline 3 & $5-4-1$ & 11,44 & 2,95 & 2,14 & 2,96 & 0,93 & 0,86 & 8,69 \\
\hline 4 & $5-4-1-2$ & 11,54 & 2,95 & 2,13 & 2,96 & 0,93 & 0,86 & 8,68 \\
\hline 5 & $5-4-1-2-3$ & 12,44 & 3,05 & 2,28 & 3,07 & 0,91 & 0,83 & 9,32 \\
\hline 6 & $5-4-1-2-3-7$ & 1,68 & $\mathbf{0 , 5 3}$ & 0,36 & $\mathbf{0 , 5 3}$ & 0,99 & 0,99 & 0,28 \\
\hline 7 & $5-4-1-2-3-7-8$ & 1,77 & 0,53 & 0,38 & 0,53 & 0,99 & 0,99 & 0,28 \\
\hline 8 & $5-4-1-2-3-7-8-6$ & 5,97 & 1,33 & 0,98 & 1,34 & 0,97 & 0,95 & 1,77 \\
\hline
\end{tabular}

ÖS: Özellik Sayısı, ÖN: Özellik Numarası 
Belirlenen tasarım parametrelerine bağlı olarak konutların soğutma yükü tahmini için oluşturulan sekiz modelin her birinde farklı sayıda özellikler kullanılmıştır. Soğutma yükü tahmininde elde edilen sonuçları değerlendirmek için kullanılan kriterler ve sonuç değerlerine( Tablo 5) göre sekiz özelliğin bir arada kullanılarak oluşturulan YSA modelinin diğerlerine göre daha başarılı olduğu belirlenmiştir.

Tablo 5. Soğutma yükü tahmini için model performansları

\begin{tabular}{cc|ccccccc}
\multicolumn{1}{c|}{ Özellikler } & \multicolumn{8}{c}{ Performans Değerlendirme Kriterleri } \\
ÖS & ÖN & MAPE & RMSE & MAD & SH & R & $\mathbf{R}^{\mathbf{2}}$ & MSE \\
\hline 1 & 5 & 12,77 & 4,21 & 3,13 & 4,23 & 0,86 & 0,75 & 17,71 \\
\hline 2 & $5-4$ & 12,29 & 3,95 & 2,96 & 3,97 & 0,86 & 0,75 & 15,59 \\
\hline 3 & $5-4-1$ & 8,04 & 2,50 & 1,92 & 2,51 & 0,92 & 0,85 & 6,24 \\
\hline 4 & $5-4-1-2$ & 9,23 & 2,76 & 2,17 & 2,78 & 0,92 & 0,85 & 7,64 \\
\hline 5 & $5-4-1-2-3$ & 8,12 & 2,52 & 1,93 & 2,53 & 0,92 & 0,85 & 6,34 \\
\hline 6 & $5-4-1-2-3-7$ & 3,47 & 1,54 & 0,99 & 1,54 & 0,99 & 0,97 & 2,36 \\
\hline 7 & $5-4-1-2-3-7-8$ & 4,37 & 1,66 & 1,18 & 1,67 & 0,98 & 0,97 & 2,76 \\
\hline $\mathbf{8}$ & $\mathbf{5 - 4 - 1 - 2 - 3 - 7 - 8 - 6}$ & $\mathbf{3 , 7 7}$ & $\mathbf{1 , 3 8}$ & $\mathbf{0 , 9 7}$ & $\mathbf{1 , 3 9}$ & $\mathbf{0 , 9 9}$ & $\mathbf{0 , 9 8}$ & $\mathbf{1 , 9 1}$ \\
\hline
\end{tabular}

ÖS: Özellik Sayısı, ÖN: Özellik Numarası

\section{Tartışma}

Makine Öğrenimi genellikle mevcut verilerden öğrenen bir bilgisayar algoritmasını tanımlamak için kullanılmaktadır. Öğrenme sürecinde kullanılan modeller önemli ölçüde verinin nispeten daha az sayıda girdi değişkenleri ile sonuç elde etmesine imkân sağlamaktadır. Son yıllarda, bina sektöründe 1sıtma ve soğutma yükleri, enerji performans vb., tahmini için çok sayıda makine öğrenimi tekniği önerilmiştir [2], [3], [11], [13], [14]. Bu teknikler, bina sistemleri hakkında hiçbir bilgi gerektirmeden verilen verileri kullanarak çeşitli girdi özellikleri ve çıktı hedefleri arasında bir ilişki oluşturmaktadır. Yapılan çalışmada binalara ait birtakım fiziksel tasarım parametrelerinin 1sıtma ve soğutma yüküne etkisinin keşfedilmesi ve bu yük değerlerinin YSA modeli ile tahmin edilmesine dayanmaktadır. Çalışma sonucunda, binaların toplam yüksekliği, duvar alanı, çatı alanı özellikleri, yük değerlerine etkisi en fazla olan özellikler olarak belirlenmiştir. Ayrıca sonuç YSA modelinde de kabul edilebilir hata paylarıyla yüklerin tahmin edilebilirliği görülmüștür. Sonuç bulguları, literatürde yer alan çalışmalarla uyumlu sonuçlar vermektedir.

\section{Sonuçlar}

Binaların tasarım sürecinde enerji performanslarının tahmin edilebilmesi, kullanım sürecinde binalarda enerji verimliliği sağlanmasında önemlidir. Son zamanlarda her alanda olduğu gibi mimarlık alanında da makine öğrenim teknikleri yer almaya başlamıştır. Farklı yöntemlerle harcanan zamandan büyük ölçüde tasarruf sağlaması enerji talep tahmininde kullanımı artırmıştır. 
YSA modelinin yüksek tahmin doğruluğu, gömülü sistemlere kolay uygulanabilirliği, bina enerji talep tahmini için uygulanabilir bir yöntem olarak görülmüştür. Ancak unutulmamalıdır ki girdi katmanını oluşturulan özelliklerin nitelikleri, modeli eğitmek için kullanılan veri sayısı, model oluşturmak için kullanılan makine öğrenim teknikleri her bir çalışma için farklılaşabilir ve elde edilen tahmin değerleri de modellere göre farklılık gösterebilir.

\section{Kaynaklar}

[1] A. Kylili and P. A. Fokaides, "European smart cities: The role of zero energy buildings," Sustain. Cities Soc., vol. 15, pp. 86-95, Jul. 2015, doi: 10.1016/J.SCS.2014.12.003.

[2] R. J. Hafner, D. Elmes, and D. Read, "Promoting behavioural change to reduce thermal energy demand in households: A review," Renew. Sustain. Energy Rev., vol. 102, pp. 205214, Mar. 2019, doi: 10.1016/J.RSER.2018.12.004.

[3] H. Zhao and F. Magoulès, "A review on the prediction of building energy consumption | Elsevier Enhanced Reader." Https://Reader.Elsevier.Com/Reader =Eu-West1\&Origincreation=20210725115410 (Accessed Jul. 25, 2021).

[4] D. Vuarnoz and T. Jusselme, "Temporal variations in the primary energy use and greenhouse gas emissions of electricity provided by the Swiss grid," Energy, vol. 161, pp. 573-582, Oct. 2018, doi: 10.1016/J.Energy.2018.07.087.

[5] A. Batish and A. Agrawal, "Building Energy Prediction for Early Design Stage Decision Support: A Review of Data-driven Techniques," in Proceedings of Building Simulation 2019: 16th Conference of IBPSA, 2020, vol. 16, pp. 1514-1521, doi: 10.26868/25222708.2019.211032.

[6] W. Gao, J. Alsarraf, H. Moayedi, A. Shahsavar, and H. Nguyen, “Comprehensive preference learning and feature validity for designing energy-efficient residential buildings using machine learning paradigms," Appl. Soft Comput. J., vol. 84, p. 105748, Nov. 2019, doi: 10.1016/j.asoc.2019.105748.

[7] R. Kumar, R. K. Aggarwal, and J. D. Sharma, "Energy analysis of a building using artificial neural network: A review," Energy Build., vol. 65, pp. 352-358, Oct. 2013, doi: 10.1016/J.ENBUILD.2013.06.007.

[8] J. S. Chou and D. K. Bui, "Modeling heating and cooling loads by artificial intelligence for energy-efficient building design," Energy Build., vol. 82, pp. 437-446, Oct. 2014, doi: 10.1016/j.enbuild.2014.07.036.

[9] M. W. Ahmad, M. Mourshed, and Y. Rezgui, "Trees vs Neurons: Comparison between random forest and ANN for high-resolution prediction of building energy consumption," Energy Build., vol. 147, pp. 77-89, Jul. 2017, doi: 10.1016/J.ENBUILD.2017.04.038. 
[10] K. Pervez Amber et al., "Energy Consumption Forecasting for University Sector Buildings," doi: 10.3390/en10101579.

[11] K. Amasyali and N. M. El-Gohary, "A review of data-driven building energy consumption prediction studies," Renewable and Sustainable Energy Reviews, vol. 81. Elsevier Ltd, pp. 1192-1205, Jan. 01, 2018, doi: 10.1016/j.rser.2017.04.095.

[12] T. Ahmad, H. Chen, Y. Guo, and J. Wang, "A comprehensive overview on the data driven and large scale based approaches for forecasting of building energy demand: A review," Energy Build., vol. 165, pp. 301-320, Apr. 2018, doi: 10.1016/j.enbuild.2018.01.017.

[13] M. Bourdeau, X. qiang Zhai, E. Nefzaoui, X. Guo, and P. Chatellier, "Modeling and forecasting building energy consumption: A review of data-driven techniques," Sustain. Cities Soc., vol. 48, p. 101533, Jul. 2019, doi: https://doi.org/10.1016/j.scs.2019.101533.

[14] T. Østergård, R. L. Jensen, and S. E. Maagaard, "Building simulations supporting decision making in early design - A review," Renewable and Sustainable Energy Reviews, vol. 61. Elsevier Ltd, pp. 187-201, Aug. 01, 2016, doi: 10.1016/j.rser.2016.03.045.

[15] S. Seyedzadeh, F. P. Rahimian, I. Glesk, and M. Roper, "Machine learning for estimation of building energy consumption and performance: a review," Visualization in Engineering, vol. 6, no. 1. 2018, doi: 10.1186/s40327-018-0064-7.

[16] A. Tsanas and A. Xifara, "UCI Machine Learning Repository: Energy efficiency Data Set," https://archive.ics.uci.edu/, 2012. https://archive.ics.uci.edu/ml/datasets/energy+efficiency (accessed Jun. 12, 2021).

[17] A. Tsanas and A. Xifara, "Accurate quantitative estimation of energy performance of residential buildings using statistical machine learning tools," Energy Build., vol. 49, pp. 560-567, Jun. 2012, doi: 10.1016/j.enbuild.2012.03.003.

[18] R. Alpar, Uygulamalı istatistik ve geçerlilik güvenirlilik: Spor, sağlık ve eğitim bilimlerinden örneklerle, 2nd ed. Ankara: Detay Yayıncılık, 2016.

[19] A. Zheng, Evaluating Machine Learning Models, 1st ed. 2015.

[20] B. Ataseven, "Yapay Sinir Ağlar1 İle Öngörü Modellemesi," Öneri Derg., vol. 10, no. 39, pp. 101-115, 2013. 